\title{
Multiple enhancers located in a 1-Mb region upstream of $P O U 3 F 4$ promote expression during inner ear development and may be required for hearing
}

\author{
Silvia Naranjo • Krysta Voesenek • Elisa de la Calle-Mustienes • Alex Robert-Moreno • \\ Haris Kokotas • Maria Grigoriadou • John Economides · Guy Van Camp • Nele Hilgert • \\ Felipe Moreno $\cdot$ Berta Alsina $\cdot$ Michael B. Petersen · Hannie Kremer · José Luis Gómez-Skarmeta
}

Received: 16 June 2010/ Accepted: 13 July 2010/Published online: 29 July 2010

(C) The Author(s) 2010. This article is published with open access at Springerlink.com

\begin{abstract}
POU3F4 encodes a POU-domain transcription factor required for inner ear development. Defects in POU3F4 function are associated with $\mathrm{X}$-linked deafness type 3 (DFN3). Multiple deletions affecting up to $\sim 900-\mathrm{kb}$ upstream of POU3F4 are found in DFN3 patients, suggesting the presence of essential POU $3 F 4$ enhancers in this region. Recently, an inner ear enhancer was reported that is absent in most DFN3 patients with upstream deletions. However, two indications suggest that additional enhancers in the POU $3 F 4$ upstream region are required for POU $3 F 4$
\end{abstract}

Electronic supplementary material The online version of this article (doi:10.1007/s00439-010-0864-x) contains supplementary material, which is available to authorized users.

S. Naranjo · E. de la Calle-Mustienes .

J. L. Gómez-Skarmeta $(\square)$

Centro Andaluz de Biología del Desarrollo, Consejo Superior

de Investigaciones Científicas, Universidad Pablo de Olavide,

Carretera de Utrera Km1, 41013 Sevilla, Spain

e-mail: jlgomska@upo.es

\section{K. Voesenek}

Department of Otorhinolaryngology,

Head and Neck Surgery, Radboud University Nijmegen

Medical Centre, Nijmegen, The Netherlands

H. Kokotas - M. Grigoriadou - M. B. Petersen

Department of Genetics, Institute of Child Health,

"Aghia Sophia" Children's Hospital, Athens, Greece

J. Economides

Department of Audiology-Neurootoloty,

Aghia Sophia Children's Hospital, Athens, Greece

A. Robert-Moreno · B. Alsina

Developmental Biology, Department of Experimental

Sciences and Health, Pompeu Fabra University,

Barcelona Biomedical Research Park, Barcelona, Spain function during inner ear development. First, there is at least one DFN3 deletion that does not eliminate the reported enhancer. Second, the expression pattern driven by this enhancer does not fully recapitulate Pou3f4 expression in the inner ear. Here, we screened a $1-\mathrm{Mb}$ region upstream of the POU $3 F 4$ gene for additional cisregulatory elements and searched for novel DFN3 mutations in the identified POU3F4 enhancers. We found several novel enhancers for otic vesicle expression. Some of these also drive expression in kidney, pancreas and brain, tissues that are known to express Pou3f4. In addition, we report a new and smallest deletion identified so far in a DFN3 family which eliminates $3.9 \mathrm{~kb}$, comprising almost

G. Van Camp · N. Hilgert

Department of Medical Genetics,

University of Antwerp, Antwerp, Belgium

F. Moreno

Unit of Molecular Genetics,

Ramón y Cajal Hospital, 28034 Madrid, Spain

H. Kremer

Department of Otorhinolaryngology, Head and Neck Surgery,

Radboud University Nijmegen Medical Centre,

Nijmegen, The Netherlands

H. Kremer

Nijmegen Centre for Molecular Life Sciences,

Donders Institute for Brain, Cognition and Behaviour,

Radboud University Nijmegen, Nijmegen, The Netherlands 
exclusively the previous reported inner ear enhancer. We suggest that multiple enhancers control the expression of Pou3f4 in the inner ear and these may contribute to the phenotype observed in DFN3 patients. In addition, the novel deletion demonstrates that the previous reported enhancer, although not sufficient, is essential for POU $3 F 4$ function during inner ear development.

\section{Introduction}

POU-domain genes encode a large family of evolutionary conserved transcription factors that contain two characteristic DNA-binding domains, a homeobox and a POU domain. They play multiple roles during animal development (reviewed in Phillips and Luisi 2000; Ryan and Rosenfeld 1997). Pou3f4 (also know as Brn4), one of the members of this family, has a complex and dynamic expression pattern in different vertebrate tissues such as the developing inner ear, brain, neural tube, kidney and pancreas (de Kok et al. 1996; Heller et al. 2004; Phippard et al. 2000; Witta et al. 1995). Studies in Xenopus indicate that Pou3f4 (originally named Xlpou2) has the potential to transform epidermis to neural fate during early development (Witta et al. 1995). Moreover, mouse models demonstrate that this gene is essential for inner ear development (Phippard et al. 2000; Phippard et al. 1999). In humans, several deletions, inversions and point mutations indicate that POU $3 F 4$ is associated with the most common form of X-linked non-syndromic deafness, deafness type 3 (DFN3) (Bitner-Glindzicz et al. 1995; de Kok et al. 1995a, b, 1996, 1997). Indeed, DFN3 patients show inner ear malformations that are similar to those found in mice lacking Pou3f4 expression (Phippard et al. 1999, 2000), indicating a conserved requirement of this gene for inner ear development in mammals and probably in other vertebrates as well.

In addition to coding sequences, some non-coding sequences display high conservation between evolutionary distant species. Their evolutionary conservation is suggested to underlie essential regulatory functions. Interestingly, the human POU3F4 gene is located on the $\mathrm{X}$ chromosome, in a $3-\mathrm{Mb}$ gene desert region enriched for highly conserved non-coding regions (HCNRs). Gene deserts enriched for HCNRs is a genomic feature characteristic of developmental genes with tightly regulated expression patterns (reviewed in Alonso et al. 2008). Indeed, many different studies have shown that HCNRs are enriched in cis-regulatory elements (reviewed in Alonso et al. 2008). Several DFN3 patients and families contain deletions that do not affect the transcribed region of POU3F4 but instead remove different portions of DNA in the desert genomic region upstream of the gene (Cremers
Fig. 1 Localization of DFN3 deletions and HCNRs in the upstream genomic region of POU3F4. Green arrows show the position of the identified enhancers. a Deletion map within $1.5 \mathrm{Mb}$ around POU3F4 as reported previously (de Kok et al. 1996; Cremers et al. 2008). Dashed lines represent the deleted regions in each patient. The red box marks the 13-kb EcoRI fragment in which the 2540 8-kb deletion is located. b Vista view showing the distribution of HCNRs within $1-\mathrm{Mb}$ upstream of POU3F4. Shown from top to bottom are mouse versus human, chicken versus human and Xenopus tropicalis versus human global alignments. Coloured peaks (purple coding, pink noncoding) indicate regions of at least $100 \mathrm{bp}$ and $75 \%$ similarity. Red dots are HCNRs with no enhancer activity in Xenopus assays. Green arrows point at the HCNRs that showed enhancer activity (also shown with green dots). Their genomic positions are depicted in green. The red box marks the 13-kb EcoRI fragment in which the $25408-\mathrm{kb}$ deletion is located. c Close-up of this 13-kb EcoRI fragment. Below is shown the new deletion identified in this work (dotted line). The blue line shows the region that was reported to have inner ear enhancer activity in mouse transgenic assays (Ahn et al. 2009)

et al. 2008; de Kok et al. 1996) (Fig. 1a). The detailed genomic analysis of these deletions prompted to define a critical region for DFN3 920-kb upstream of the gene (de Kok et al. 1996) and to propose the presence of cisregulatory sequences essential for POU $3 F 4$ expression in the developing inner ear in this critical region (de Kok et al. 1996). Most of the identified microdeletions encompass a critical region of $\sim 8 \mathrm{~kb}$ from a 13-kb EcoRI fragment (patient 2540) (Cremers et al. 2008; de Kok et al. 1996). Indeed, a recent report showed that, in mouse transgenic assays, a human 3.4-kb DNA fragment containing a HCNR located within this 13-kb fragment can promote expression in several inner ear structures derived from the otic mesenchyme (Ahn et al. 2009). This includes the temporal bone, spiral ligament, and the mesenchyme underlying the sensory epithelium of the utricle, saccule and semicircular canals (Ahn et al. 2009), most being structures affected in DFN3 patients or in mouse models for this disease (de Kok et al. 1995b; Phippard et al. 1999, 2000). However, the expression pattern promoted by this HCNR did not fully recapitulate that of the endogenous Pou3f4 gene (Ahn et al. 2009). This, together with the fact that not all $5^{\prime}$ deletions remove the critical 13-kb interval (Cremers et al. 2008; de Kok et al. 1996), indicate that other important inner ear enhancers are likely to contribute to POU $3 F 4$ expression in this territory.

Here, we report the enhancer survey of multiple HCNRs located in a region of 1-Mb upstream of Xenopus Pou3f4 in both Xenopus and zebrafish by using transgenic assays. We identify three novel Pou $3 f 4$ regulatory regions capable of activating expression in the developing otic vesicle, as well as in other Pou3f4 expression domains. These novel regulatory regions are likely contributing to POU $3 F 4$ inner ear expression and are therefore candidate regions to be affected in DFN3 patients. In addition, we identify a new 


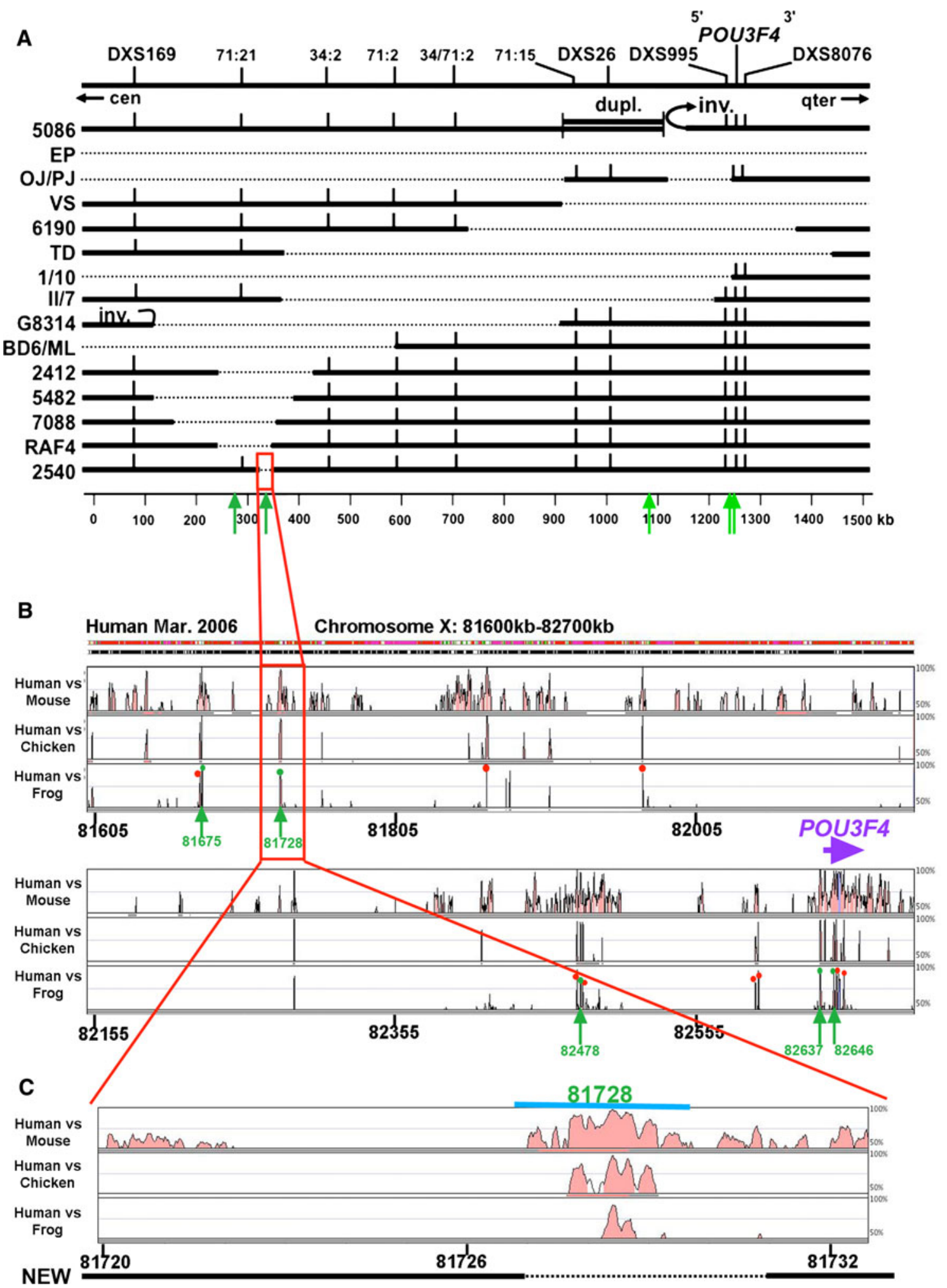

DFN3 family that contains a minimal deletion of $3.9 \mathrm{~kb}$ that precisely removes the reported HCNR with inner ear enhancer activity within the $13-\mathrm{kb}$ critical interval. These results support the idea that, despite the existence of other otic vesicle enhancers, this one is critical for POU $3 F 4$ activity in the developing inner ear. 


\section{Materials and methods}

\section{Patients}

Family W06-205 with five affected males is shown in the pedigree from Fig. 4a. The hearing loss in four of them was already severe in childhood. For subject II.4 pure tone thresholds have never been determined. He was said to be born deaf but he developed some speech after big efforts of his mother. Individual II.6 is profoundly hearing impaired and did not develop speech. In patient III.2, the hearing loss is stable and severe to profound and speech development was very poor. Only for individuals IV.1 and IV.2, audiological data are available from childhood. The hearing loss of subject IV.1 was moderate at the age of 27 months and severe at 6 years. In individual IV.2, the hearing loss was less severe. He had moderate hearing loss at 10 and 12 years of age, with a significant air bone gap in the lower frequencies. He underwent stapes surgery at 12 years of age and stapes gusher occurred during surgery. There are no indications for hearing loss in any of the female mutation carriers of generations II-IV but audiometry has not been performed.

All patients or their legal representatives gave written informed consent for the study.

\section{Genetic analyses}

Genomic DNA of family members was isolated from peripheral blood samples by a standard salting out procedure (Miller et al. 1988). Analysis of 14 STR markers uniformly dispersed over the $\mathrm{X}$ chromosome was performed using standard methodology on an ABI 3130 DNA sequencer (Applied Biosystems, CA, USA). DNA sequencing of the complete $\mathrm{POU} 3 \mathrm{~F} 4$ coding region was done by PCR amplification in overlapping fragments and sequencing using the same ABI sequencer. Sequences of primers employed to characterize the deletion in family W06-205 by amplification of fragments of the proximal region are provided in Supplementary Table 1 . DMSO was added to $10 \%$ of the volume of the PCR for the amplicons 4 and 5. Amplification was performed with Phusion High-Fidelity DNA Polymerase (New England Biolabs, MA, USA). Primers have been designed with Primer3plus (http://www.bioinformatics.nl/ cgi-bin/primer3plus/primer3plus.cgi).

Functional reporter analyses in Xenopus and zebrafish

All HCNRs were selected with the vista browser (http:// pipeline.lbl.gov/cgi-bin/gateway2) using the default parameters (regions of at least $100 \mathrm{bp}$ and $70 \%$ similarity). HCNRs were amplified by PCR from Xenopus tropicalis genome using the primers listed in Supplementary Table 2.
The PCR fragments were subcloned in PCR8/GW/TOPO (Invitrogen, CA, USA) vector and, using the gateway technology (Invitrogen, CA, USA), transferred to the corresponding destination enhanced green fluorescent protein (EGFP) reporter vectors recently described (Bessa et al. 2009; Pittman et al. 2009) for I-SceI or Tol2 mediated transgenesis in Xenopus or zebrafish, respectively. Embryos expressing GFP were analyzed by observation of fluorescence. Xenopus embryos were then fixed and processed for whole mount in situ hybridization to detect GFP mRNA.

Xenopus and zebrafish in situ hybridization

EGFP antisense RNA probes were prepared from cDNAs using digoxigenin (Roche, Basel, Switzerland) as label. Xenopus and zebrafish specimens were prepared, hybridized and stained as described (Harland 1991; Tena et al. 2007).

\section{Results}

Identification of novel Pou3f4 cis-regulatory elements

We have examined the enhancer activity of multiple HCNRs present within 1-Mb upstream of Pou3f4 by using Xenopus and zebrafish transgenic assays. The identified HCNRs were conserved from human to frog and located in the genomic region in which most DFN3 deletions map (Fig. 1a). We amplified 16 HCNRs (Supplementary Table 2) from the Xenopus tropicalis genome and cloned them in the PCR8/GW/TOPO vector. We have named these HCNRs according to the position of their human orthologous sequences, shown in kilobases, on the $\mathrm{X}$ chromosome of the NCBI human genome assembly 18. The cloned HCNRs were transferred to vectors compatible with SceI or Tol2 mediated transgenesis in Xenopus or zebrafish, respectively (Bessa et al. 2009; Pittman et al. 2009). In these vectors, the HCNRs are placed upstream of the proximal promoter of the Xenopus or zebrafish gata2 gene driving the expression of the EGFP reporter gene. This promoter alone has no activity during embryogenesis neither in zebrafish nor Xenopus.

We first generated transient Xenopus transgenic embryos for all 16 HCNRs. From them, only five of these HCNRs (81675, 81728, 82478, 82637, and 82646; Fig. 1b) promoted reproducible reporter gene expression in different transgenic animals. All of them were active in a subset of regions expressing the endogenous Pou3f4 gene (Fig. 2). We confirmed the enhancer activity of these five HCNRs by generating different stable zebrafish transgenic lines for each region by using the same Xenopus genomic sequences. For 

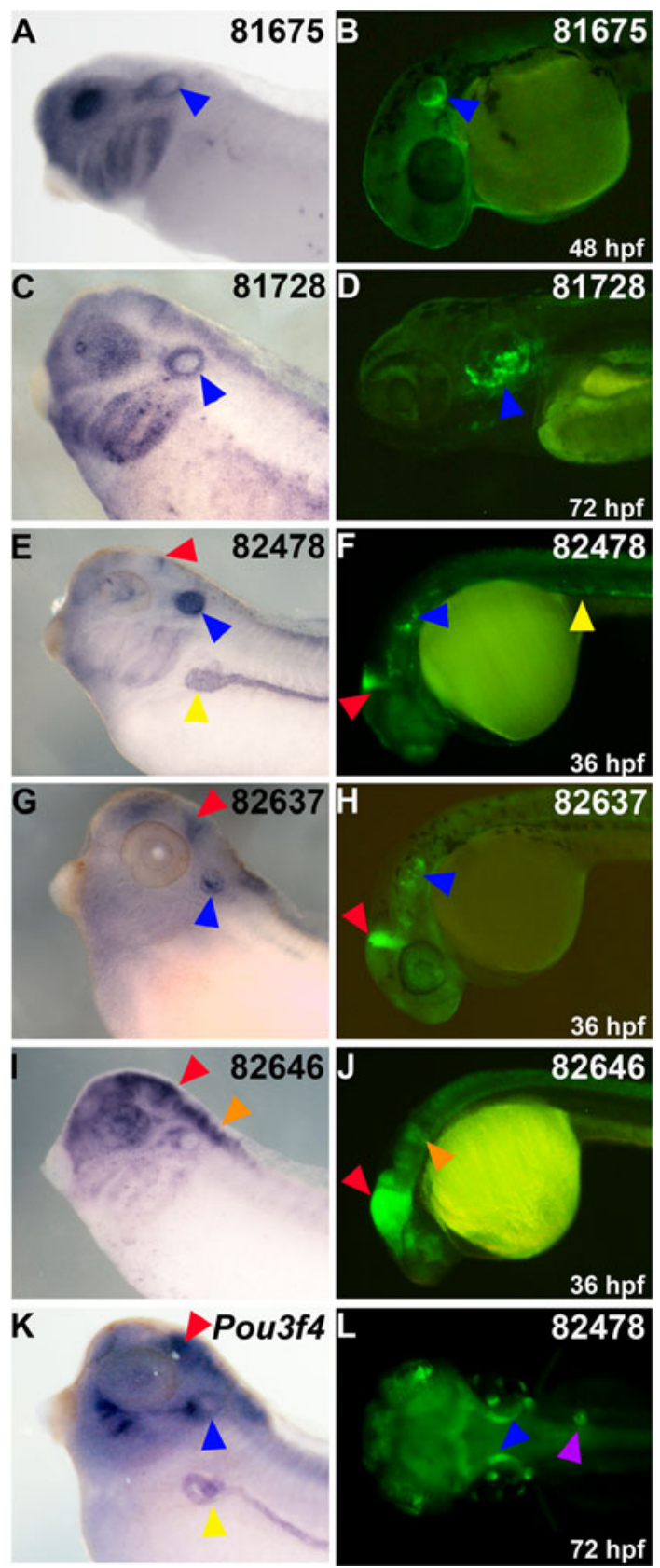

Fig. 2 Expression patterns promoted by different Pou3f4 HCNRs in Xenopus and zebrafish transgenic assays. Xenopus embryos show in situ hybridization to detect EGFP mRNA in fixed transgenic animals while zebrafish embryos show EGFP in living transgenic specimens. All panels, except (l) that show a dorsal view, are lateral views of transgenic Xenopus (a, c, e, $\mathbf{g}, \mathbf{i})$ at stage 35 or transgenic zebrafish $(\mathbf{b}, \mathbf{d}, \mathbf{f}, \mathbf{h}, \mathbf{j}, \mathbf{l})$ at 36-72-h post fertilization (hpf). The position of the HCNRs in the human genome is shown in the upper right corner of each panel. Different tissues are pointed at with coloured arrowheads. Blue otic vesicle, red midbrain, orange hindbrain, yellow kidney and purple pancreas. Note the equivalent patterns promoted by each HCNR in Xenopus and zebrafish transgenic embryos. $\mathbf{k}$ Expression pattern of Xenopus Pou $3 f 4$

all five HCNRs, we observed equivalent reporter gene expression in zebrafish as compared to Xenopus (Fig. 2) in several domains, further confirming its specificity. In addition to element HCNR 81728 , which is located $922-\mathrm{kb}$ upstream of POU $3 F 4$ and has recently been shown to be active in the otic capsule in mouse transgenic assays (Ahn et al. 2009), the HCNRs located at positions 81675 (970-kb upstream), 82478 (170-kb upstream) and 82637 (12-kb upstream) promoted inner ear expression of EGFP in both Xenopus and zebrafish models (Fig. 2). The expression of the HCNR at 81675 was almost completely confined to the developing ear, with low background expression in the branchial arch and the eye in Xenopus embryos (Fig. 2a, b). In contrast, elements 82478 and 82637 also promoted EGFP expression in the midbrain/hindbrain boundary that is most prominently visible in the zebrafish transgenic lines (Fig. 2e-h). In addition, HCNR 82478 was also found to be active in the kidney and the pancreas (Fig. 2e, f, 1). These tissues are all known to express Pou3f4 (Fig. 2k) (de Kok et al. 1996; Heller et al. 2004; Phippard et al. 2000; Witta et al. 1995). Finally, the HCNR at position 82646 induced expression in the brain and spinal cord (Fig. 2i, j). This expression pattern is identical to that found in mouse transgenic assays with a 6-kb sequence from the mouse Pou3f4 promoter region that contains the orthologous sequence (Heydemann et al. 2001).

During inner ear development, Pou3f4 is expressed in the periotic mesenchyme (Phippard et al. 1998, 1999). To better characterize the expression pattern promoted by the new identified enhancers in the inner ear domain, we performed transverse sectioning of transgenic zebrafish embryos carrying the different enhancers at $65-75 \mathrm{~h}$ post fertilization. Enhancers at position 81675 and 82637, as well as the previous characterized at 81728 , promote expression in the periotic mesenchyme (Fig. 3a, b, d, red arrows). Unexpectedly, all these enhancers were active in the otic epithelium (Fig. 3, white arrows), a tissue that seems to be devoid of Pou3f4 expression (Phippard et al. 1998, 1999). This was also occurring for the enhancer within HCNR 82478, which was not promoting expression in the periotic mesenchyme but strongly in the pronephros (Fig. 3c, yellow arrows). It is possible that the activity of all these enhancers in the otic epithelium in transgenic embryos reflects a low level of the endogenous Pou3f4 expression in these cells. Alternatively, the activity in these regions may only be observed when the Pou3f4 enhancers are not in their genomic context with other cis-regulatory elements. Interestingly, in mouse transgenesis assays, the enhancer at position 81728 also drives expression in some epithelial cells of the otic vesicle (Ahn et al. 2009).

\section{Characterization of a new DFN3 deletion}

To determine the possible association of deletions in HCNRs $81675,81728,82478$, and 82637 with a DFN3 phenotype, we tested five index cases for deletions in these 


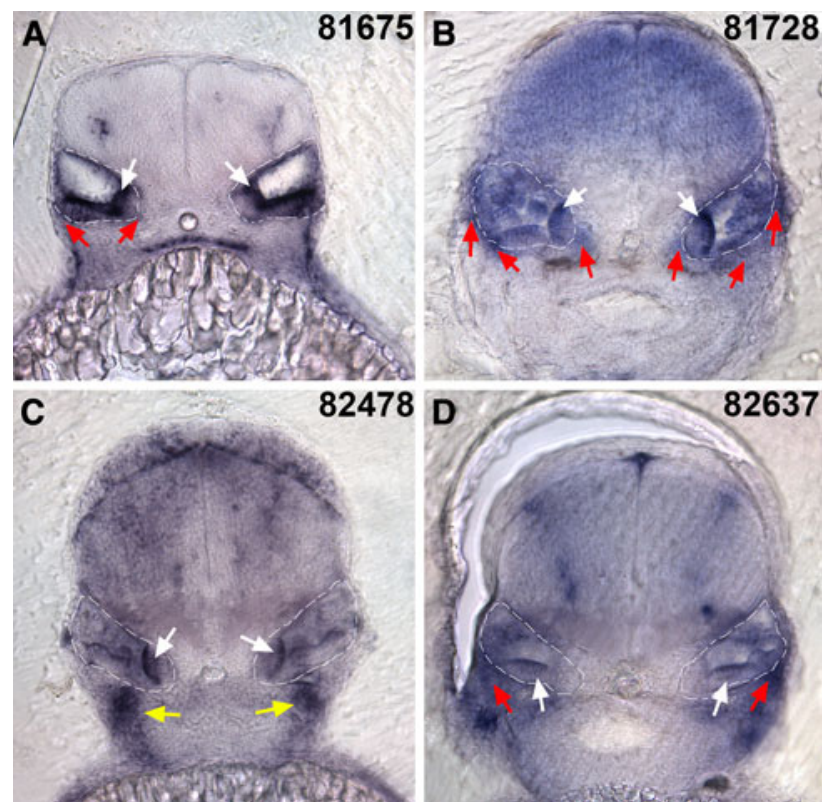

Fig. 3 Transverse sections at the level of the otic vesicle of 65-75 hpf embryos showing the expression patterns promoted by the different Pou3f4 HCNRs in stable zebrafish transgenic lines. All panels show in situs hybridization to detect EGFP mRNA in fixed embryos from the different transgenic lines. Note that enhancers at positions 81675 (a), 81728 (b) and 82637 (d) promoted expression, although in somehow different areas, in the periotic mesenchyme (red arrows). In addition, all enhancers are active in the otic epithelium (white arrows) and enhancer 82478 (c) is, in addition, active in the developing kidneys (yellow arrows)

HCNRs. Mutation analysis of the protein-coding region of POU3F4 did not reveal any putatively pathogenic mutations in these patients. Only in the proband of family W06-205 an indication for a deletion was obtained for one of the HCNRs, namely 81728 which is located $\sim 920-\mathrm{kb}$ upstream of POU $3 F 4$ within the 13-kb EcoRI fragment known to harbour an $\sim 8$-kb deletion (patient 2540) (de Kok et al. 1996). Family W06-205 of Greek origin presented with mixed hearing loss and segregation in the family was compatible with X-linked inheritance (Fig. 4a). Linkage analysis with STR markers across the $\mathrm{X}$ chromosome revealed linkage to a region containing the POU3F4 gene (Xq21.1), with a maximum LOD score of 2.1. The characterization of the deletion was initiated by using five sets of primers for PCR (1-5; Supplementary Table 2) in patient II.6, his mother (I.2) and a control individual. The amplicons cover the 13-kb EcoRI fragment containing the deletion in patient 2540. All primer sets revealed a PCR fragment of the expected size in all three individuals except primer set 2 with which no amplification occurred in the individual II.6 (data not shown). Subsequently, three series of PCR primers (a-f, I-IV, and $\Delta$; Supplementary Table 2) were developed to determine the breakpoint. With primer set $\Delta$, we amplified a fragment of $\sim 400 \mathrm{bp}$ in the patient, a fragment of the same length in the carrier female and in addition a fragment of the expected size of $\sim 4.3 \mathrm{~kb}$ in both the carrier and the control individual. By sequencing the 400-bp breakpoint spanning PCR fragment, the size of the deletion could be determined to be 3,902 bp (Fig. 4b) encompassing nucleotides 81727184-81731085 (Human genome assembly 18). This deletion segregated with the disease in the family as was tested by PCR with primer set $\Delta$. In all patients and carriers, the 400-bp fragment could be amplified but not in healthy males or in spouses of the carriers (Fig. 4a). Carrier statuses of females who are not obligate carriers are not shown for privacy reasons. Primer set $\Delta$ did not reveal fragments of aberrant size in 100 normal hearing Greek males or in 50 control females. The $3.9-\mathrm{kb}$ region that is deleted in affected males contains HNCR 81728 that is present in the 13-kb region that encompasses the smallest deleted region known so far (patient 2540) (Fig. 1c). Moreover, the reporter construct used in the paper by Ahn et al. (2009) contain a 3,370-bp genomic region that almost completely encompass the deletion we have identified.

\section{Discussion}

Breakpoint analysis of multiple deletions in different DFN3 patients suggests that cis-regulatory elements essential for POU3F4 expression and inner ear development are located within $\sim 900-\mathrm{kb}$ upstream of the gene (de Kok et al. 1996). Since most DFN3 deletions include the genomic fragment deleted in DFN3 patient 2540 (de Kok et al. 1996), an essential enhancer should be present within the 13-kb region that contains this $\sim 8-\mathrm{kb}$ deletion. Accordingly, an inner ear enhancer at HCNR 81728 was recently reported (Ahn et al. 2009). Here, we show that HCNR 81728 is functionally conserved in Xenopus and zebrafish. Moreover, the newly identified deletion, that precisely remove this HCNR and almost no additional neighbouring DNA, further demonstrates that this regulatory element is essential for POU $3 F 4$ function during inner ear development. Nevertheless, the fact that there is one DFN3 deletion (II/7) that removes about 800 -kb upstream of the gene but keeps the enhancer 81728 intact (Cremers et al. 2008; de Kok et al. 1996) (Fig. 1a), suggests that this enhancer, although essential, is not sufficient for POU3F4 expression and function during ear development. In the original report (de Kok et al. 1996), the II/7 deletion was uncorrectly depicted to be associated with a paracentric inversion which was later corrected (Cremers et al. 2008). Indeed, the paracentric inversion is associated with the deletion G8314 and not with II/7, as shown here (Fig. 1a). The existence of additional otic vesicle enhancer is further supported by the expression promoted by HCNR 81728 
Fig. 4 Genetic analysis of family W06-205. a Pedigree of family W06-205 and segregation of the deletion in the family. Filled squares represent DFN3 males. $\Delta$ deletion, + wildtype. The genotype of females who are not obligate carriers has not been indicated for privacy reasons. b Sequence chromatogram showing the deletion breakpoints in patient II.6. Above this chromatogram, the deletion is schematically indicated
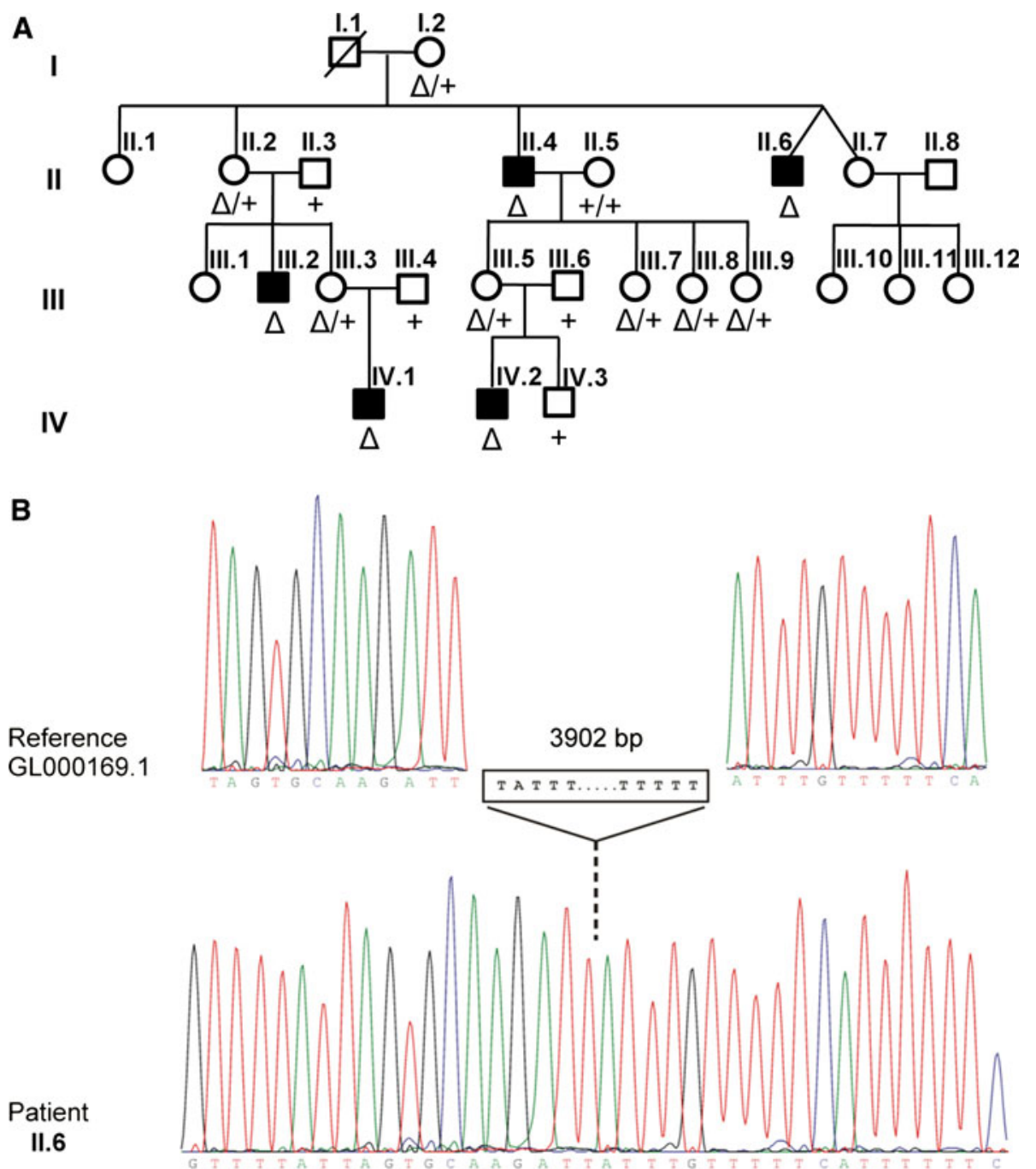

which does not fully reproduce the Pou3f4 pattern in the developing ear (Ahn et al. 2009).

By analyzing the activity of 15 additional HCNRs present within 1-Mb upstream of POU3F4, we have found three novel inner ear enhancers at 970-, 170- and 12-kb upstream of the gene. This further suggests that the expression of $\mathrm{POU} 3 \mathrm{~F} 4$ during inner ear development likely depends on several regulatory elements. In addition to the identified enhancers distributed along this vast $1-\mathrm{Mb}$ genomic interval, others may exist in less conserved noncoding sequences or in regions not conserved at all, as has been shown for other loci (McGaughey et al. 2008). The contribution of enhancers other than HCNR 81728 to POU3F4 function during inner ear development may be significant, as can be inferred from deletion II/7 (Fig 1a). Evaluation of the clinical information provided for family W06-205 and the families with larger and overlapping or non-overlapping deletions did not reveal indications for a correlation between the severity of the hearing loss and the size of the deletion and/or the number of the ear HCNRs located in the deletion. This is further corroborated by the differences in the severity of the hearing impairment between affected males in family W06-205. Also, the hearing loss in family II/7 in which HCNR 81728 is present was described to be severe in all affected males with no or minimal speech development (Robinson et al. 1992). Therefore, we can conclude that the presence of HCNR 81728 is essential but not sufficient for normal ear function.

Some of the studied enhancers not only promote expression in the developing inner ear but also in other Pou3f4 expressing tissues such as the brain, kidney and pancreas. In addition, we have confirmed the presence of a neural enhancer in a HCNR positioned at 3-kb upstream of the gene, which was previously detected in mouse transgenic assays (Heydemann et al. 2001). These results indicate that, as has been found for many other developmental genes (see for example de la Calle-Mustienes et al. 2005 and Jeong et al. 2006), the dynamic Pou3f4 expression pattern is determined by multiple cis-regulatory elements, being some of them partially redundant. 
Why developmental genes, such as POU3F4, often possess multiple cis-regulatory elements that promote expression in partially overlapping domains? A recent report demonstrates that, in Drosophila, redundant enhancers become essential under stressing conditions. These results strongly suggest that redundant $c i s$-regulatory elements contribute to phenotypic robustness under environmental and genetic variability (Frankel et al. 2010). Therefore, the novel regulatory elements that are likely to contribute to the expression of POU3F4 in the inner ear may well carry small deletions or point mutations in DFN3 patients in which no POU $3 F 4$ point mutations, deletions or major genomic rearrangements have been detected so far.

Acknowledgments We are most grateful to S. M. Sato for the Xenopus Pou3f4 probe and we wish to thank members of family W06-205 for their participation in this study. This work was supported by grants from the Spanish Ministry of Education and Science (BFU2007-60042/BMC, Petri PET2007_0158, CSD2007-00008) and Junta de Andalucía (Proyecto de Excelencia CVI-3488) to JLG-S, and the Oticon Foundation (Denmark) to MBP. CABD is institutionally supported by CSIC, Universidad Pablo de Olavide and Junta de Andalucía.

Open Access This article is distributed under the terms of the Creative Commons Attribution Noncommercial License which permits any noncommercial use, distribution, and reproduction in any medium, provided the original author(s) and source are credited.

\section{References}

Ahn KJ, Passero F Jr, Crenshaw EB 3rd (2009) Otic mesenchyme expression of Cre recombinase directed by the inner ear enhancer of the Brn4/Pou3f4 gene. Genesis 47:137-141

Alonso ME, Pernaute B, Crespo M, Gomez-Skarmeta J, Manzanares M (2008) Understanding the regulatory genome. Int J Dev Biol 53:1367-1378

Bessa J, Tena JJ, de la Calle-Mustienes E, Fernandez-Minan A, Naranjo S, Fernandez A, Montoliu L, Akalin A, Lenhard B, Casares F, Gomez-Skarmeta JL (2009) Zebrafish enhancer detection (ZED) vector: a new tool to facilitate transgenesis and the functional analysis of cis-regulatory regions in zebrafish. Dev Dyn 238:2409-2417

Bitner-Glindzicz M, Turnpenny P, Hoglund P, Kaariainen H, Sankila EM, van der Maarel SM, de Kok YJ, Ropers HH, Cremers FP, Pembrey $M$ et al (1995) Further mutations in Brain 4 (POU3F4) clarify the phenotype in the X-linked deafness, DFN3. Hum Mol Genet 4:1467-1469

Cremers FPM, Cremers CWRJ, Kremer H (2008) POU3F4 and mixed deafness with temporal bone defect (DFN3). In: Epstein CJ, Erickson RP, Wynshaw-Boris A (eds) Inborn errors of development. Oxford University Press, San Francisco, pp 1042-1047

de Kok YJ, Merkx GF, van der Maarel SM, Huber I, Malcolm S, Ropers HH, Cremers FP (1995a) A duplication/paracentric inversion associated with familial X-linked deafness (DFN3) suggests the presence of a regulatory element more than $400 \mathrm{~kb}$ upstream of the POU3F4 gene. Hum Mol Genet 4:2145-2150 de Kok YJ, van der Maarel SM, Bitner-Glindzicz M, Huber I, Monaco AP, Malcolm S, Pembrey ME, Ropers HH, Cremers FP (1995b) Association between X-linked mixed deafness and mutations in the POU domain gene POU3F4. Science 267:685-688

de Kok YJ, Vossenaar ER, Cremers CW, Dahl N, Laporte J, Hu LJ, Lacombe D, Fischel-Ghodsian N, Friedman RA, Parnes LS, Thorpe P, Bitner-Glindzicz M, Pander HJ, Heilbronner H, Graveline J, den Dunnen JT, Brunner HG, Ropers HH, Cremers FP (1996) Identification of a hot spot for microdeletions in patients with X-linked deafness type 3 (DFN3) $900 \mathrm{~kb}$ proximal to the DFN3 gene POU3F4. Hum Mol Genet 5:1229-1235

de Kok YJ, Cremers CW, Ropers HH, Cremers FP (1997) The molecular basis of X-linked deafness type 3 (DFN3) in two sporadic cases: identification of a somatic mosaicism for a POU3F4 missense mutation. Hum Mutat 10:207-211

de la Calle-Mustienes E, Feijoo CG, Manzanares M, Tena JJ, Rodríguez-Seguel E, Letizia A, Allende ML, Gómez-Skarmeta JL (2005) A functional survey of the enhancer activity of conserved non-coding sequences from vertebrate Iroquois cluster gene deserts. Genome Res 15:1061-1072

Frankel N, Davis GK, Vargas D, Wang S, Payre F, Stern DL (2010) Phenotypic robustness conferred by apparently redundant transcriptional enhancers. Nature. doi:10.1038/nature09158

Harland R (1991) In situ hybridization: an improved whole mount method for Xenopus embryos. Methods Cell Biol 36:685-695

Heller RS, Stoffers DA, Liu A, Schedl A, Crenshaw EB 3rd, Madsen OD, Serup P (2004) The role of Brn4/Pou3f4 and Pax6 in forming the pancreatic glucagon cell identity. Dev Biol 268:123-134

Heydemann A, Nguyen LC, Crenshaw EB 3rd (2001) Regulatory regions from the Brn4 promoter direct LACZ expression to the developing forebrain and neural tube. Brain Res Dev Brain Res 128:83-90

Jeong Y, El-Jaick K, Roessler E, Muenke M, Epstein DJ (2006) A functional screen for sonic hedgehog regulatory elements across a $1 \mathrm{Mb}$ interval identifies long-range ventral forebrain enhancers. Development 133:761-772

McGaughey DM, Vinton RM, Huynh J, Al-Saif A, Beer MA, McCallion AS (2008) Metrics of sequence constraint overlook regulatory sequences in an exhaustive analysis at phox $2 b$. Genome Res 18:252-260

Miller SA, Dykes DD, Polesky HF (1988) A simple salting out procedure for extracting DNA from human nucleated cells. Nucleic Acids Res 16:1215

Phillips K, Luisi B (2000) The virtuoso of versatility: POU proteins that flex to fit. J Mol Biol 302:1023-1039

Phippard D, Heydemann A, Lechner M, Lu L, Lee D, Kyin T, Crenshaw EB 3rd (1998) Changes in the subcellular localization of the Brn4 gene product precede mesenchymal remodeling of the otic capsule. Hear Res 120:77-85

Phippard D, Lu L, Lee D, Saunders JC, Crenshaw EB 3rd (1999) Targeted mutagenesis of the POU-domain gene Brn4/Pou3f4 causes developmental defects in the inner ear. J Neurosci 19:5980-5989

Phippard D, Boyd Y, Reed V, Fisher G, Masson WK, Evans EP, Saunders JC, Crenshaw EB 3rd (2000) The sex-linked fidget mutation abolishes Brn4/Pou3f4 gene expression in the embryonic inner ear. Hum Mol Genet 9:79-85

Pittman AM, Naranjo S, Webb E, Broderick P, Lips EH, van Wezel T, Morreau H, Sullivan K, Fielding S, Twiss P, Vijayakrishnan J, Casares F, Qureshi M, Gomez-Skarmeta JL, Houlston RS (2009) The colorectal cancer risk at $18 \mathrm{q} 21$ is caused by a novel variant altering SMAD7 expression. Genome Res 19:987-999

Robinson D, Lamont M, Curtis G, Shields DC, Phelps P (1992) A family with $\mathrm{X}$-linked deafness showing linkage to the proximal $\mathrm{Xq}$ region of the X chromosome. Hum Genet 90:316-318 
Ryan AK, Rosenfeld MG (1997) POU domain family values: flexibility, partnerships, and developmental codes. Genes Dev 11:1207-1225

Tena JJ, Neto A, de la Calle-Mustienes E, Bras-Pereira C, Casares F, Gomez-Skarmeta JL (2007) Odd-skipped genes encode repressors that control kidney development. Dev Biol 301:518-531
Witta SE, Agarwal VR, Sato SM (1995) XIPOU 2, a noggininducible gene, has direct neuralizing activity. Development 121:721-730 